\title{
Practical Engineering Behavior of Egyptian Collapsible Soils, Laboratory and In-Situ Experimental Study
}

\author{
Naema A. Ali \\ Construction Engineering and Management Department, Pharos University in Alexandria, Alexandria, Egypt \\ Email: Dr_Naemaali1@yahoo.com
}

How to cite this paper: Ali, N.A. (2021) Practical Engineering Behavior of Egyptian Collapsible Soils, Laboratory and In-Situ Experimental Study. Open Journal of Civil Engineering, 11, 290-300.

https://doi.org/10.4236/ojce.2021.113017

Received: July 27, 2021

Accepted: August 20, 2021

Published: August 23, 2021

Copyright (๑) 2021 by author(s) and Scientific Research Publishing Inc. This work is licensed under the Creative Commons Attribution-NonCommercial International License (CC BY-NC 4.0).

http://creativecommons.org/licenses/by-nc/4.0/

\begin{abstract}
In many sites on Egypt desert roads collapsible soils is broadly classified as a problematic soils containing silty fine sand which is cemented with low density and low degree of saturation which is susceptible to a large and sudden reduction in their volume upon inundation, with or without vibration in its stress. Four sites have been studied for new urban, roads and industry work sits, related to increase in natural water content. These soils go through radical rearrangement of their particles, causing sudden changes in the stress-deformation behavior which cause differential settlement of foundation and roads. This change in volume can lead to foundation failures and worth of damages under ground public facilities and infrastructure. In this study, the search program is developed to establish their different behavior under wetting in two phases: field and laboratory work. The obtained results are useful in mapping the trend of the factors affected in assessing soil collapsibility rate or collapse potentials which are observed in construction with volume change problems. The major factors observed are the natural structure skeleton of the soil particle and its grain size and mechanism of soil sedimentation. The field collapse potentials value assigned for these tested sites along Alexandria-Cairo desert road indicated that the field measured collapsibility potentials are smaller than those measured on the same extracted undisturbed samples in laboratory by $15 \%$, which can be saved in coast, change in proposed collapsibility improvement method and change in select foundation type. Also, field tests evaluate the collapsibility rate with time and highlight that environmental history and natural soil structure in field are the important factors affected on these soil collapse, and also, knowledgeable by collapsible soils during wetting in these sites studied.
\end{abstract}

\section{Keywords}

Natural Water Content, Natural Soil Structure, Collapsibility Properties, Field 


\section{Introduction}

In practicing many problematic soils which are met geotechnical engineers in description characterization of collapsible, it should be estimated the extent wetting depth and degree of wetting, to choice the foundation design or approximately treatment of collapse settlements or strains of these soils. Since collapsible soils are mostly transported by wind and deposited in arid or semi-arid regions, thus they are created in unsaturated state with low density and low natural degree of saturation. Since collapsible soils are mostly transported by wind and deposited in arid or semi-arid regions, thus they are created in unsaturated state with low density and low natural degree of saturation. This soil typically collapses when it increases in its water content and exposes a sudden decrease in its volume with or without increase in normal vertical stress, making downfall a problematic soil. In Egypt geographical location of these collapsible soil was observed within the northern portion of the western desert including Borg $\mathrm{Al}$ Arab/King-Marriot regions and Alexandria/Cairo desert highway road, and round of the Cairo city in Egypt, as shown in Figure 1. As reported in many references soil collapse potential has been affected by initial water content of this soil, initial dry density, pressure at wetting, wetting front inside soil depth and depth of collapsible soil layer [1] [2] [3] [4].

Many researchers and studies [3]-[8] investigated the laboratory mechanical behavior of collapse soil and reported that the major soil categories that lead to substantial collapse involved filling and soil classified as CL and ML soils, conferring to the Unified Soil Classification System, and also, soil deposit which has a low initial dry density, low moisture content and low plasticity, susceptible collapse [8] [9] [10]. ASTM D5333-92 defines a "collapse index $\left(\mathrm{I}_{\mathrm{e}}\right)$ " as the deferential vertical strain between the wet and dry conditions at a pressure of 200 $\mathrm{kPa}$ [6] [11]. There are various empirical relationships that have been proposed and established to evaluate collapse potential of collapsible soils from their natural properties [1] [5] [12] [13].

In references [1] [3] [8] [10] the others reported that the high bonding strength of collapsible soil at dry state in field can be brought low shear strength changes with the disturbance of soil samples. Also, they found good correlation between a field collapse test and modified collapse potential test results on drive testes despite a tester zone ratio of $56 \%$. Reference [1] described the judgment between dry densities rate for thick-walled and thin-walled tube samplers with in-situ dry densities measured by the sand cone method (ASTM D-1557) [6] [12].

From the discussion of how to achieve undisturbed collapse soil samples in many references, it can be seen that there is effect of state of samples on soil collapse predictions. Most observations of the effects of sample disturbance for 


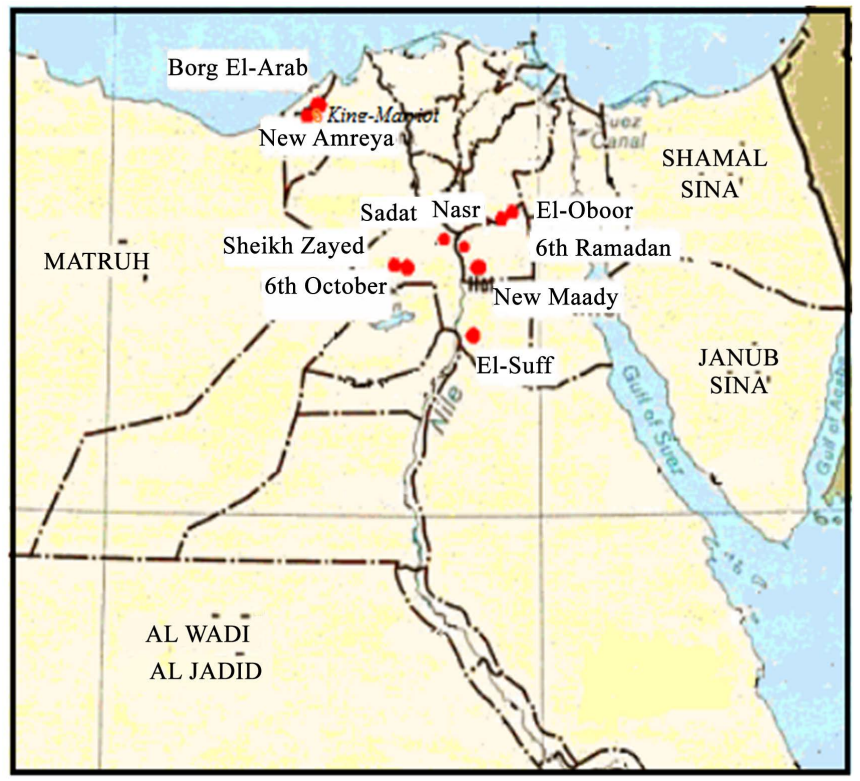

Figure 1. Geographic of the Egypt collapse soil areas.

collapsible soils have been made relative to difference in compression, (natural soil structure) and changes in dry density. While block sampling has the slightest effect on density, it is subject to other limitations which bound its practicality [8] [12]. Reference [14] summarized many various approaches for interpreting the wetting induced collapse system of collapsible loess soil deposits.

Many studies attempted to predicted hydro-collapse performance using the soil water characteristic curve considering the critical suction and collapse rate under inundation and had been concluded that only two parameters, critical suction and collapse rate, required to predict collapse behaivour under inundation in their study condition [15]. The researcher report "Collapsible soils go through three distinct phases in response to matric suction decrease during wetting: pre-collapse phase, collapse phase and post-collapse phase".

Other studies had been interpreted the collapse soil, hydraulic properties as they contain a connection in the steady zone and the flow velocity. Also, suggested a new conceptual model of suction profile adopted field water flow in the unsaturated soil to be interpreted ex-tending the water continuity equation [15] [16].

Regardless of these consequences and the several researches that are existing, more study is still essential in learn of soil collapsibility.

Normally, the most generally process used for reliable proposal and predicted potential collapse is the laboratory-Oedometer collapse test. The different geological soil property is the main key to reveal and quantify soils collapsibility. Changes in the micro structural arrangement of particles within the soil skeleton would control the mechanical behavior of collapse soil when subjected to varying inundation conditions. This study has been investigating the effect of sample disturbance on soil collapse predictions. The in-situ test have been considered the actual influence of the particle size, void ratio, degree of saturation and nat- 
ural density on the soil collapsibility, where the field testing is the most positive and express resources to classify and assess soil collapsibility. In-situ Collapse Test Device, shown in Figure 2, was conducted to investigate the field collapsibility.
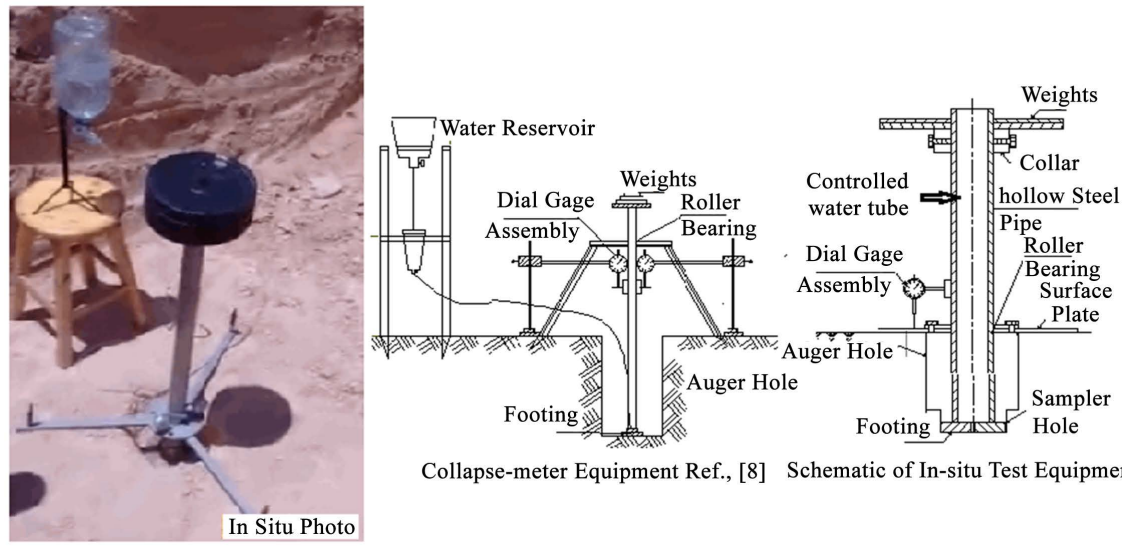

Collapse-meter Equipment Ref., [8] Schematic of In-situ Test Equipment

(a)
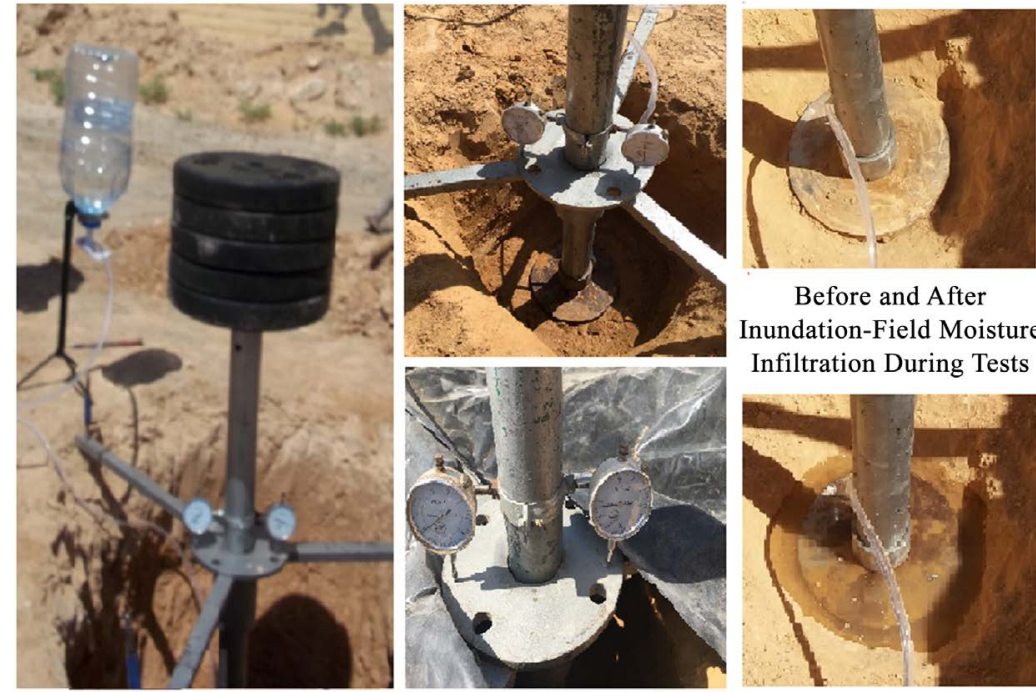

Before and After Inundation-Field Moisture Infiltration During Tests

(b)
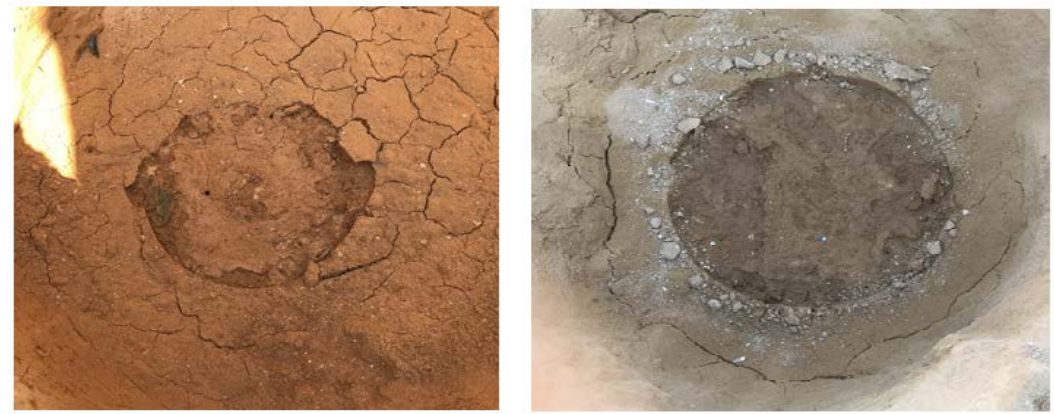

(c)

Figure 2. (a) In-situ test equipment (collapse-meter); (b) In-situ collapsibility potential measured, test pit has been covered most of experimental time to minimize the evaporation of water; (c) In-situ observed collapsibility and failure modes for different zone study. 
The experimental work in four sites conducted in this study has demonstrated that if initial natural density, natural soil structures, void ratio, and natural water content are not appropriately controlled, following wetting can cause substantial collapse strains. Also, the study highlighted on methods used for measured collapsibility degree/potential in the laboratory as implication of study soil deposits as database for considered zones in Alexandria Cairo desert road. All field tests have been conducted at depth $1.50 \mathrm{~m}$. from ground surface to avoid active depth which the seasonal degree of saturation variations occurred.

In this paper in situ study different site areas in Borg El Arab, King-Marriot, and Alexandria/Cairo highway desert road at $\mathrm{Km} 57$ and $\mathrm{Km} 82$ from Alexandria in natural stat for focused on the effect of variation on moisture content on collapsibility potential and its rate with time. Also, compare the performance of collapsibility in zones study. Proof of identity and description of collapsible soils become a new condition for future industrial/urban planning developments in these areas. Therefore, the probable hazards of these soils should be representative, as well as to deliver with applied tools for study, and treatment. Laboratory and field study used to expect collapse potential since the acting vertical stress by measuring vertical soil deformation at its natural moisture content and its density when wetting. Tests in situ on natural soils without any disturbance are the most sure and direct resource to classify and quantity true soil collapse. In spite of these significances and several studies that are available, more researches are still essential to study actual soil collapsibility.

\section{Subsoil, Characterization and Geotechnical Performance}

The soil collapse potential is evaluated from single odometer test (ASTM D5333) [6] [11]. Particle size distribution, void ratio and density impact on the soil collapsibility have been studied using (ASTM). In this study different sites have been selected for sampling and in-situ testing, as mentioned, Borg El Arab, King-Marriot, and Alexandria/Cairo highway desert road at Km 57 and $\mathrm{Km} 82$ from Alexandria sites.

Samples have been collected from different locations at study areas to determine their geotechnical natural and mechanical properties. Undisturbed soil block samples were collected for laboratory tests cut from pits excavated at different sites at depth ranges between $1.6-3.00 \mathrm{~m}$ from ground surface. Table 1 shows the collected geotechnical properties results from laboratory testing program on undisturbed soil samples of considering block collapsible soils of study sites. The measured value of Collapsibility Potential $C_{p}(\%),\left(C_{p}=\Delta H / H_{i}\right)$ was recorded as, average values of four samples for each site, percentage of soil component contained and natural geotechnical soil properties obtained from laboratory testing results.

\section{Geotechnical Field Investigation Program}

Plate load tests, with in-situ pseudo-consolidation test [12], were achieved using 
Table 1. Index properties and collapsibility potential of undisturbed soil samples.

\begin{tabular}{ccccc}
\hline Soil properties & Borg El Arab & King-Marriot & Km 57 & Km 82 \\
\hline Initial Water Content \% & 7.6 & 7.2 & 7.8 & 8.8 \\
Natural Unit Weight kN/m ${ }^{3}$ & 13.6 & 14.2 & 14.1 & 13.8 \\
Percentage of Sand \% & 24.6 & 20.4 & 31.2 & 34.4 \\
Percentage of Silt \% & 67.2 & 57.5 & 49.4 & 50.2 \\
Percentage of Clay \% & 8.2 & 22.2 & 19.4 & 15.4 \\
Lab Collapsibility Potential C $\%$ & 10.8 & 4.4 & 7.1 & 6.7 \\
Initial voids ratio $e_{\mathrm{p}}$ & 0.79 & 0.52 & 0.61 & 0.59 \\
Plasticity Limits L.L \% & 28 & 39 & 40 & 42 \\
P.L \% & 19 & 18 & 22 & 25 \\
\hline
\end{tabular}

in-situ collapse testing apparatuses, as shown in Figure 2. In situ test directed on natural collapsible soil without any change in its natural soil structures, void ratio, and moisture content. After finishing all field tests, depth of moisture infiltration has been evaluated up to depth $6 \mathrm{D}$. The details of each component of the equipment similar to one developed by Ferreira and Fucale [12], with a description of the pseudo-consolidation test apparatuses.

\section{Field Test for Interested Zones Study}

In this study In-Situ Collapse Toole firstly applies stress on natural collapse soil at bottom level of a shallow augured hole, test pit, Figure 2. The figures illustrate that saturate natural soil after a certain stress level by water tube directed contact with limit water tank. The footing model in-situ has been loaded to failure to investigate the wet ultimate bearing capacity. The same stages of plate load test, vertical loads, weights, have been applied addition incremental sequence, load-settlement relationship recorded during all the load stage and its duration. For each load increment, settlement was measured with time till ceased, after which next increment was applied. To study inundation effect, controlled inundated with 10/15 liter of water is allowed seeping on the soil surface at hole bottom via the flexible plastic-controlled water tube to simulate inundation in field due to any water leakage from pipe lines. The calculated amount of Collapsibility Potential in field collapsibility, $\mathrm{C}_{\mathrm{p}}(\%),\left(\mathrm{C}_{\mathrm{p}}=\Delta \mathrm{H} / \mathrm{H}_{\mathrm{i}}\right)$, where Hi considers the water infiltration depth measured after ending test. Procuring samples for water content and soil properties determination after finish each test up to depth 6D.

\section{Discussion Results}

Collapse plate loading/Collapse-meter tests were performed on collapsible soil surface at different tested sites considered. The test holes' dimensions, which excavated in sites are approximately $600 \times 600 \mathrm{~mm}$ and have been tested at different depth (1.5, 1.75 and $2.0 \mathrm{~m})$, under hydro-collapse vertical stress 150, 300, 
450 and $600 \mathrm{kPa}$. Each load and unload stage were maintained during $24 \mathrm{hr}$. and final load established up to $72 \mathrm{hr}$. after inundation. Result of case study collapsibility at depth $2.00 \mathrm{~m}$ from ground level is presented and discussed in this paper. Figure 3 and Figure 4 show the post-inundation relationship between applied pressure and its recount settlement of the collapsible soil under central concentric load after additional deformation occurred.

The measured value of Collapsibility Potential $\mathrm{C}_{\mathrm{p}}(\%),\left(\mathrm{C}_{\mathrm{p}}=\Delta \mathrm{H} / \mathrm{H}_{\mathrm{i}}\right)$ was recorded for four samples for each site in laboratory and also, in situ for three places related to each site, the relationship between $\mathrm{C}_{\mathrm{p}} \%$ in each site in field and lab are plotted in Figure 5, which indicated the variation of collapse Potential $C_{p} \%$. The results obtained clearly indicate that the collapses of the different soils between each site conform well to the result in reference [12]. It is attention to note that the field collapse potentials measured for all tested sites are lesser than those measured in the laboratory for the same undisturbed block samples by $(15 \%$ $16 \%)$. Thus, it can be said the laboratory collapsibility results are more conservative. The figures indicated that because the diverse of environmental/geological soil possessions is important to explaining and measuring soils collapsibility in four site study. Also, it can be observed that the total time of collapse development is extra for collapsible soils with fewer grades natural water content compared to collapsible soils with a higher grade of inundation.

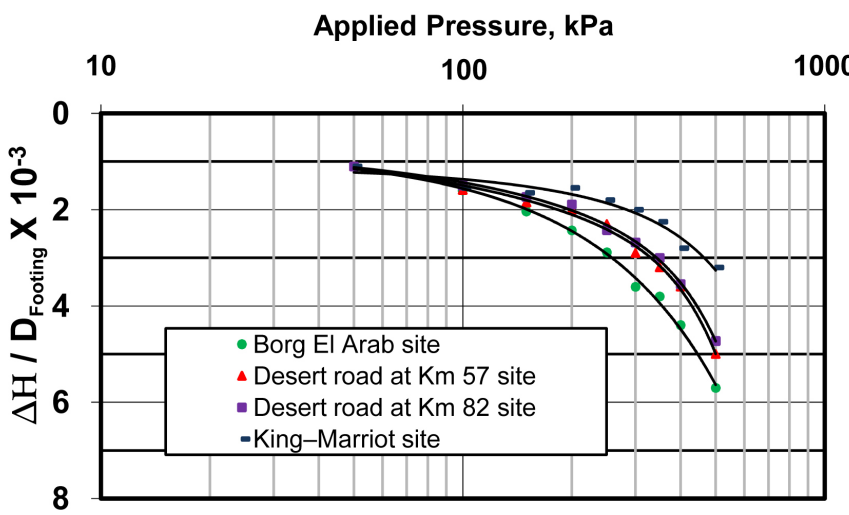

Figure 3. Settlement-stress relationship under footing flooded at stress $50 \mathrm{kPa}$.

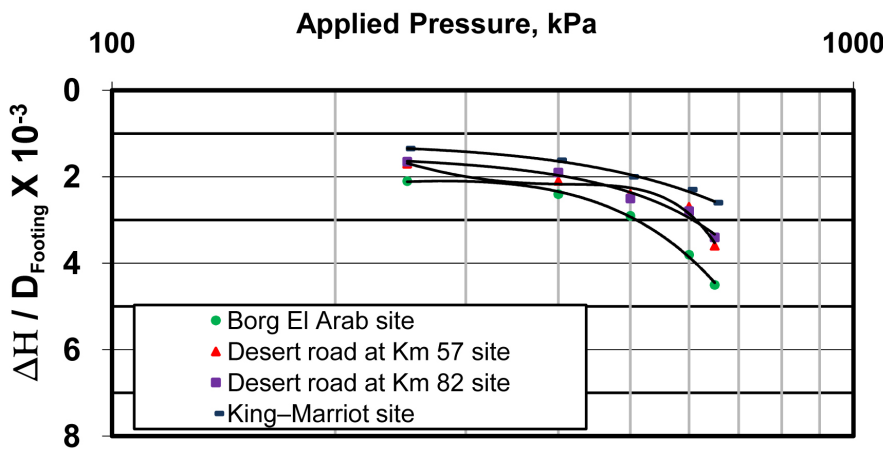

Figure 4. Settlement-stress relationship under footing flooded at stress $250 \mathrm{kPa}$. 


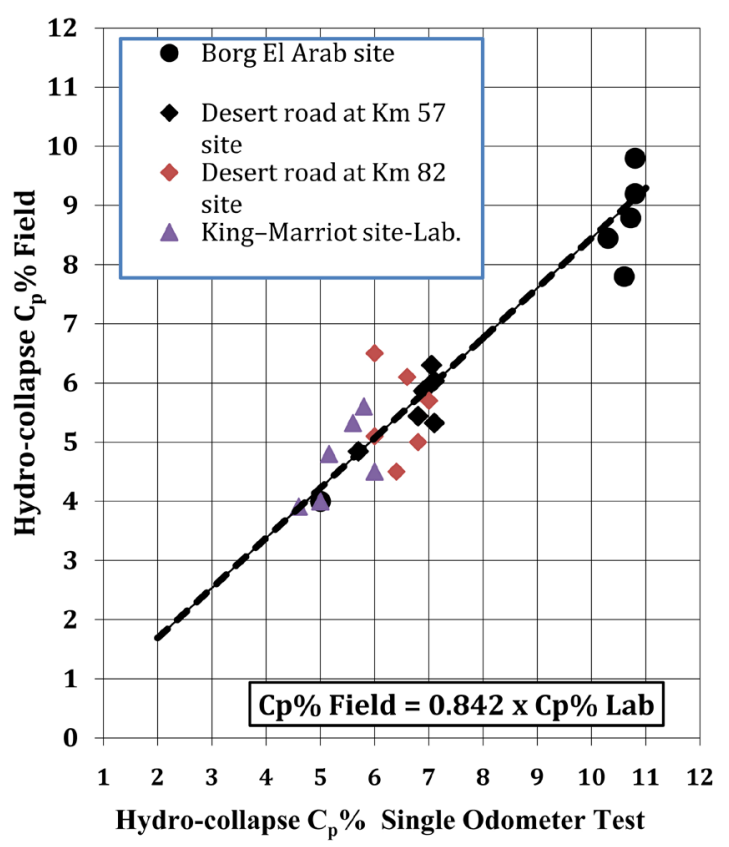

Figure 5. Relationship between hydro-collapse potential obtained in field and laboratory tests.

Figure 6 presents the general hydro-collapse behavior for tested sites in laboratory and in situ. The predicted values of the hydro-collapse from plotted measured values curves are depending on the level of vertical pressure applied and time of wetting. The field collapsibility result indicated that the settlement varies from soil to soil in four sites with time and cease after a certain time if normal stress and wetting not change. But under subsequent wetting and load additional settlement occurred. The excess normal stress and wetting change the soil skeleton, soil suction bonding or cementing agent and weakness or destroys the bonding causing shear failure as reported in reference [15] [16].

The soil trained deformation when water was added and after 72 hours for water quantity 12.0 liters, the soil deformation was equal to $10.29 \mathrm{~mm}$. at the end of test sample rings were extracted at different depth under tested loaded area to assessment unite weight and water content up to 6D depth to catch water infiltration depth due to inundation. These field results can be useful to predict the decrease in final matric-suction due to wetting [17]. Also, it was observed during test all the water was drained after different limited times in four sites study and the time for the same water volume is not exceed 45 mints from starting inundation, the supply water infiltration slowly. The comparative between average value of measured Collapsibility Potential $\mathrm{C}_{\mathrm{p}} \%$, values for four samples for each site in laboratory and in situ study illustrates in Figure 7. The figure indicated that the higher in clay percentage in collapse soil as in (King-Marriotsite, Clay \% $=22.2 \%)$ the more possibility decreases in collapse potential, $\mathrm{C}_{\mathrm{p}}$. On the other hand, the figure indicates the influence of clay fraction on the collapse soils in sites studied. 
Time ( $\min$ )
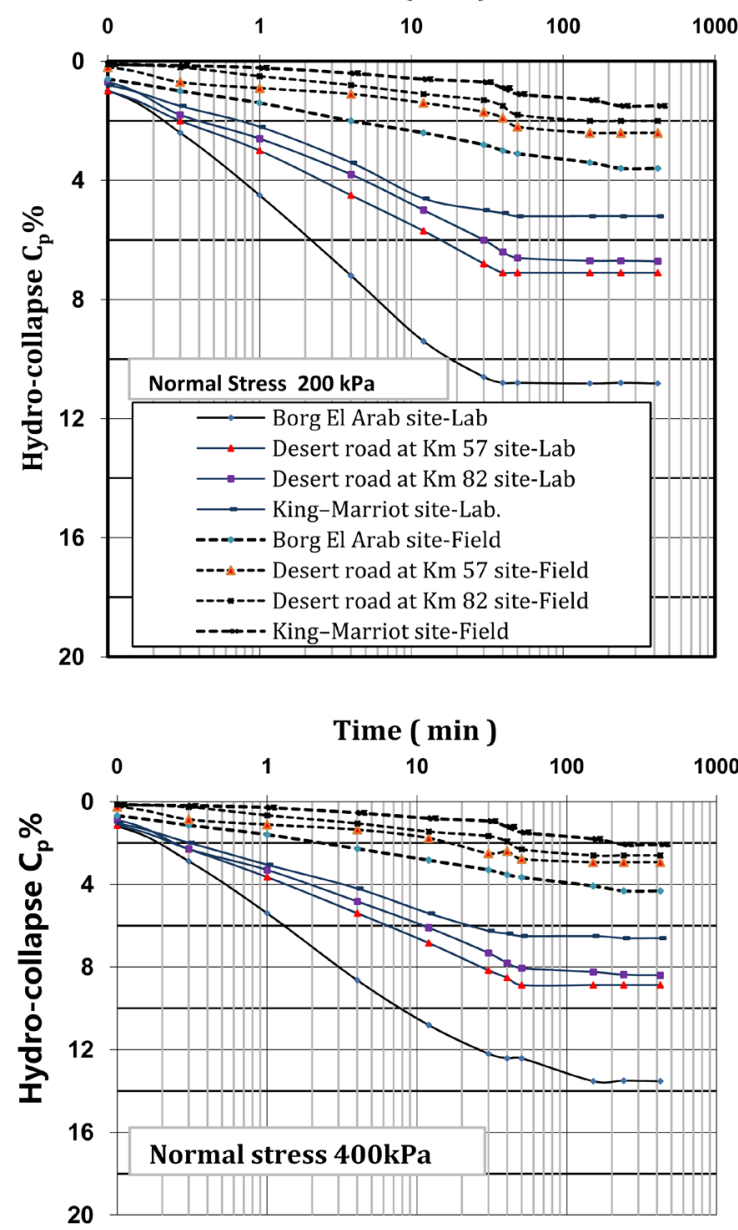

Figure 6. Hydro-collapse-time (after footing flooded at stress 200/400 kPa).

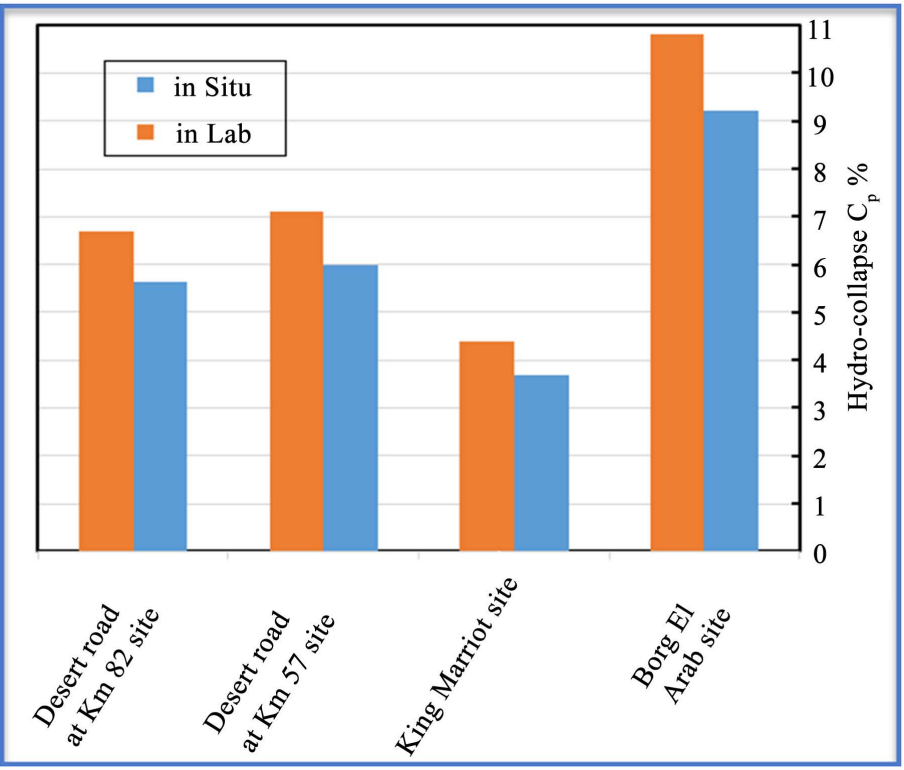

Figure 7. Comparative between obtained hydro-collapse potential $\mathrm{C}_{\mathrm{p}} \%$ in field and laboratory tests. 
The total collapsibility indicated that King-Marriot collapsible soil in study site can be considered to attitude serviceable collapse problems when clay percentage increases and are similar to collapse soil from many parts of the worlds. Also, the permeability of tested collapsible soils, refined water decreases with time after initial saturation. Collapsible soil after inundation displays large displacement than dry soil, thus site drainage is very important factor to be considered during design and construction foundations on these soils. Also, the results obtained concluded that if the thickness of collapse soil layer increased the obvious settlement increases, and penetration depth of wetting increases inside collapse soil. It can be concluded that use in situ technique under the wetted loaded area is effective in evaluating the actual collapse potential.

\section{Conclusions}

Based on in situ and laboratory obtained results presented in this study of different sites study, the following decisions and conclusions can be drawn,

- The feasibility in situ collapse potential evaluated can be applied on a broader range of collapsible soils to assess its actual and natural performance. Also, field test considered all surrounding and environmental conditions of the soil mass tested in situ.

- The study focuses on the importance of varying possibilities of actual collapse soil in situ for investigating the risk of foundation design and its construction process.

- For a specified initial stress under which inundation process occurs, minor values of density lead to the higher strain or soil failure. Also, deformation due to inundation depends on time.

- Field testing is the greatest certain and direct resources to classify and evaluate actual collapsibility potential of soil and also, it can be another suitable gauge of relative stability of soil.

- It is of interest to note that the field collapse potentials measured for all tested sites are smaller than those measured in the laboratory for the same undisturbed samples at the same applied stress, by (15\% - 16\%), which can be saved in coast, change in proposed collapsibility improvement method and change in select foundation type.

\section{Acknowledgements}

Results in this research were obtained and developed by the author, some of soil tests were performed at Soil Mech. Lab of Civil Engineering Dpt., Higher Institute of Engineering \& Technology, King-Marriot, Alexandria, Egypt. The author likes to greatly appreciate them.

\section{Conflicts of Interest}

The author declares no conflicts of interest regarding the publication of this paper. 


\section{References}

[1] Anne, C.O., Samoon, N. and Ian, J. (2014) Laboratory Testing Regime for Quantifying Soil Collapsibility. World Academy of Science, Engineering and Technology International Journal of Environmental, Ecological, Geological and Geophysical Engineering, 8, 849-854.

[2] Farulla, A., Ferrari, C. and Romero, A.E. (2010) Volume Change Behaviour of a Compacted Silty Clay during Cyclic Suction Changes. Canadian Geotechnical Journal, 47, 688-703. https://doi.org/10.1139/T09-138

[3] Maleki, M. and Bayat, M. (2012) Experimental Evaluation of Mechanical Behavior of Unsaturated Silty Sand under Constant Water Content Condition. Engineering Geology, 141-142, 45-56.

[4] Rezaei, M., Ajalloeian, R. and Ghafoori, M. (2012) Geotechnical Properties of Problematic Soils Emphasis on Collapsible Cases. International Journal of Geosciences, 3, 105-110. https://doi.org/10.4236/ijg.2012.31012

[5] Cristopher, T.S. (2013) Expedient Mitigation of Collapsible Loess in Northern Afghanistan. International Journal of Geoengineering Case Histories, 2, 252-257.

[6] Egyptian Code of Practice of Soil Mechanics and Foundation Engineering (Part 1/5), 2010.

[7] Fookes, P.G. and Parry, R.H.G. (1993) Engineering Characteristics of Arid Soils. First International Symposium on Engineering Characteristics of Arid Soils, London, 6-7 July 1993, Vol. 1, 289-292.

[8] Sun, D.A., Sheng, D. and Xu, Y. (2007) Collapse Behaviour of Unsaturated Compacted Soil with Different Initial Densities. Canadian Geotechnical Journal, 44, 673-686. https://doi.org/10.1139/t07-023

[9] Adnan, B.A. and Erdil, T.R. (1992) Evaluation and Control of Collapsible Soils. Journal of Geotechnical Engineering, 118, 1491-1504. https://doi.org/10.1061/(ASCE)0733-9410(1992)118:10(1491)

[10] Dudley, H.H. (1970) Review of Collapsing Soils. ASCE Journal of Soil Mechanics and Foundation Division, 96, 925-947.

[11] Annual Book of ASTM Standards Designation: D5333-03 (2003). Standard Test Methods for Measurement of Collapse Potential of Soils, Vol. 04.09.

[12] Ferreira, S.R.M. and Fucale, S. (2014) Evaluation of the Collapsibility of Soils in the Semiarid Region Pernambuco, Brazil. Journal of Civil Engineering and Architecture, 83, 1285-1292.

[13] Samir, I.S. (2014) The Assessment of the Collapse Potential of Fills during Inundation Using Plate Load Tests. Life Science Journal, 11, 1001-1006.

[14] Li, P., Vanapalli, S. and Li, T. (2016) Review of Collapse Triggering Mechanism of Collapsible Soils Due to Wetting. Journal of Rock Mechanics and Geotechnical Engineering, 8, 256-274. https://doi.org/10.1016/j.jrmge.2015.12.002

[15] Xie, W.-L., Li, P., Vanapalli, S.K. and Wang, J.-D. (2018) Prediction of the Wetting-Induced Collapse Behaviour Using the Soil-Water Characteristic Curve. Journal of Asian Earth Sciences, 15, 259-268.

[16] Hou, X.K., Vanapalli, S.K. and Li, T.L. (2019) Water Flow in Unsaturated Soils Subjected to Multiple Infiltration Events. Canadian Geotechnical Journal, 57, 366-376. https://doi.org/10.1139/cgj-2018-0566

[17] Zhong, S.L., Assia, B., Feth, E.M.D., Nabil, A.B., Said, T., Hanane, S. and Jean, M.F. (2017) Global Representation of the Drying-Wetting Curves of Four Engineering Soils: Experiments and Correlations. Springer, Berlin. 